\title{
AS REDES SOCIAIS DIGITAIS E SUA INFLUÊNCIA NA SOCIEDADE E EDUCAÇÃO CONTEMPORÂNEAS
}

\author{
V. L. C. SANTOS* E J. E. SANTOS \\ Universidade Federal do Rio Grande do Norte \\ nallaezeri@gmail.com
}

Artigo submetido em janeiro/2014 e aceito em dezembro/2014

DOI: 10.15628/holos.2014.1936

\section{RESUMO}

Objetivamos refletir sobre a presença e influência das redes sociais digitais na sociedade e educação, buscando identificar sua importância enquanto ferramenta de comunicação e informação, bem como também aspectos ideológicos inerentes a esse fenômeno. Para tanto, foi feito levantamento bibliográfico e uma pesquisa exploratória com usuários e docente de uma escola pública da zona urbana de uma cidade norte-riograndense, buscando respostas à problemática deste estudo, ou seja: qual a influência das redes sociais digitais na sociedade e na educação contemporâneas? Dessa forma, pudemos constatar, dentre outros resultados suas influências na organização política dos cidadãos quanto à luta por melhorias sociais; na maneira de perceber o espaço-tempo-atual; na concepção de autonomia e de vivência; no consumo; na aquisição do conhecimento, bem como no processo de ensino e aprendizagem, fenômenos que precisam ser pensados, sobretudo pelas instituições de ensino.

PALAVRAS-CHAVE: Redes Sociais Digitais, Sociedade, Educação.

\section{THE DIGITAL SOCIAL NETWORKS AND THEIR INFLUENCE ON SOCIETY AND CONTEMPORARY EDUCATION}

\begin{abstract}
We aim to reflect on the presence and influence of the online social networks in society and education, search to identify its importance as a communication and information tool, and also ideological aspects inherent to this phenomenon. Therefore, it was done bibliographic and user exploratory research with teaching in a public school of the urban area of a town norte-rio-grandense, seeking answers to the problems of this study, in other words: what is the influence of digital social networks in contemporany society and in
\end{abstract}

education? Thus so, we observed, among other results their influence in the political organization of the citizens how much the struggle for social improvements; in the way they of perceive the current space-time; in the concept of autonomy and experience; in the consumption; in the acquisition of knowledge, and also in the teaching and learning process, phenomena that need to be thought, especially by educational institutions.

KEYWORDS: Digital Social Networks, Society, Education. 


\section{INTRODUÇÃO}

"Para ter eficácia, o processo de aprendizagem deve, em primeiro lugar, partir da consciência da época em que vivemos"

(Milton Santos em: Técnica, Espaço, Tempo, 2008, p. 115).

A advertência que o geógrafo Milton Santos faz, na epígrafe acima, nos é oportuna e extremamente necessária no mundo de hoje, haja vista o processo de aprendizagem está inserido numa realidade socioeconômica e política cada vez mais complexa e desafiadora, exigindo do profissional docente e daqueles que buscam pensar a sociedade, extremo esforço e dedicação para, a partir da consciência da época em que se vive, buscar a apreender a realidade (FREIRE, 2006), em que se está inserido e, "em nossa época, o que é representativo [...] é a chegada da técnica da informação por meio da cibernética, da informática, da eletrônica" (SANTOS, 2010, p. 25). Sendo assim, o objetivo deste trabalho é refletir sobre a presença e influência das redes sociais digitais, fruto deste período e meio técnico-científico-informacional, na sociedade e educação, buscando identificar sua importância enquanto ferramenta de comunicação e informação, bem como também suas consequências decorrentes dessa nova realidade socioespacial, refletindo alguns aspectos ideológicos, já que essas ferramentas possibilitam novas maneiras de participação na/da sociedade, permitindo troca de informações e opiniões, encontros, disponibilização e troca de fotos/arquivos, dicas, namoro, proposta de emprego etc., ou seja, possibilitam novos sistemas de ações.

O período técnico-científico-informacional, atual período do espaço geográfico e da sociedade, começa praticamente após a Segunda Guerra Mundial, porém se dando de fato nos anos 1970. É o período em que vivemos, caracterizado por um meio produzido e em produção pela indissociabilidade e presença cada vez mais intensa da técnica, da ciência e da informação, como componentes dos sistemas de objetos e dos sistemas de ações que formam o espaço geográfico e a sociedade contemporâneos (SANTOS, 2009); (SANTOS; SILVEIRA, 2002).

A componente informação é quem vai ser, nesse período, o grande regedor/desencadeador "[...] das ações definidoras das novas realidades espaciais" (SANTOS, 2008 , p. 89), sendo difundida por computadores e aparelhos celulares, dando ao meio e aos seus objetos e sociedade uma organização típica desse processo, tornando esse meio um território com a ação direta ou indireta da ciência, da tecnologia e da informação.

Tal realidade socioespacial é um fenômeno decorrente da implementação, no substrato econômico e social, político e espacial, dos novos sistemas de objetos e sistemas de ações 1 pautados na técnica, na ciência e na informação, proporcionando ações e formas de comunicações diversas. Em outras palavras, é o período de novas redes técnicas, que configura

\footnotetext{
1 “O espaço é hoje um sistema de objetos cada vez mais artificiais, povoado por sistemas de ações igualmente imbuídos de artificialidade, e cada vez mais tendentes a fins estranhos ao lugar e a seus habitantes. Os objetos não têm realidade filosófica, isto é, não nos permitem o conhecimento, se os vemos separados dos sistemas de ações. Os sistemas de ações também não se dão sem os sistemas de objetos. Sistemas de objetos e sistemas de ações interagem. De um lado, os sistemas de objetos condicionam a forma como se dão as ações e, de outro lado, o sistema de ações leva à criação de objetos novos ou se realiza sobre objetos preexistentes. É assim que o espaço encontra a sua dinâmica e se transforma" (SANTOS, 2009, p. 63).
} 
novas relações sociais, que acabam permitindo a circulação de ideias, mensagens2, pessoas e mercadorias, num ritmo acelerado, criando a interconexão entre os lugares de maneira sincrônica, muito embora se dando essa instalação desses aparatos técnicos, científicos e informacionais, nos lugares e na vida das pessoas, de forma diacrônica, pois "os processos espaços-temporais não são homogêneos, nem tampouco homogeneizam [...]" (CASTRO, 2008, p. 320) todos os territórios ao mesmo tempo.

Com efeito, isso fez com que tivéssemos uma realidade socioespacial caracterizada com novos comportamentos e com novas necessidades que do ponto de vista das intencionalidades parece insaciáveis. Nesse sentido, Milton Santos nos lembra que, "O meio geográfico atual, graças ao seu conteúdo em técnica e ciência [e diríamos nós em informação], condiciona os novos comportamentos humanos, e estes, por sua vez, aceleram a necessidade da utilização de recursos técnicos, que constituem a base operacional de novos automatismos sociais3" (SANTOS, 2009. p. 256; grifos nossos).

Já que é fato que as redes sociais estão presentes em nosso dia a dia, até que ponto elas podem influenciar a sociedade e a educação? Assim sendo, as redes sociais digitais, como estão sendo desenvolvidas e utilizadas pelos usuários, são dinamizadoras de novos saberes e/ou conhecimentos, identidades e formas de relação? De que maneira poderão alterar as relações sociais e sua formação ao longo da vida, no sentido de que há outras interferências ou instâncias coexistentes e intermitentes, sobre o usuário, que estimulam mudanças de pensamento e de ações, é o caso da família e da escola?

Quanto a estrutura, este trabalho está assim organizado: num primeiro momento, fazemos alguns apontamentos sobre redes sociais digitais, buscando conceituá-las e discuti-las a partir de alguns autores que demarcam, sobremaneira, a presença desses meios comunicacionais no espaço-tempo-atual, buscando destacar ainda neste subitem, as redes digitais mais conhecidas e acessadas pelos usuários brasileiros, quais sejam, Orkut, Facebook, Twitter e Instagram, suas especificidades e funções.

Num outro momento, trazemos à tona a discussão sobre as redes sociais digitais e sua influência na sociedade e educação contemporâneas. Para podermos entender tal fenômeno enfocamos "a Sociedade em Rede" e as redes sociais digitais para além do espaço virtual - sua influência no processo de ensino e aprendizagem, apresentando os resultados decorrentes da pesquisa, refletindo suas possibilidades enquanto mecanismo de apoio à ação didáticopedagógica, valendo ressaltar, portanto, que as ideais e reflexões discutidas não se constituem como arcabouço axiomático, isto é, um conjunto de reflexões encerradas em si mesmas, mas abertas à críticas e sugestões.

\footnotetext{
${ }^{2}$ A distribuição das mensagens e a interatividade como resposta deste processo só existem de acordo com o diagrama de Paul Baran, discutido por Franco (2009), porque as redes sociais digitais, aqui em questão, são distribuídas, ou seja, se configuram a partir do padrão todos-com-todos, sem hierarquias. Baseado nisto, e tendo como referências as mudanças sociais, coagulamos com o pensamento de que o local se torna global (FRANCO, 2003).

${ }^{3}$ Entenda-se por automatismos sociais o conjunto de sistemas de ações sociais que hoje se dá amparado nas novas tecnologias, que tem a internet como elemento constitutivo possibilitando, assim, um raio de ações e práticas que invadem a sociedade e a educação de forma a condicionar os indivíduos.
} 


\title{
2 REVISÃO BIBLIOGRÁFICA
}

\subsection{Redes Sociais Digitais: conceitos e exemplos}

Podemos afirmar, sem equívoco, que neste período técnico-científico-informacional, a internet, através das tecnologias da informação e comunicação (computador, celulares, smartphones, tablets), enquanto possibilidade de comunicação e informação está modificando a maneira como as pessoas se relacionam, aprendem e se comunicam. Nesse sentido, uma "convergência dos momentos" (SANTOS, 2009, p. 196) se configura no substrato socioespacial em que se conjugam, num mesmo direcionamento, mídia e tecnologias de informação e comunicação configurando, em grande medida, o aumento das redes sociais digitais que se tornam cada dia mais latentes na cultura e sociedade contemporâneas.

Consideramos as redes sociais digitais como um meio de possibilidades, estabelecido a partir dos elementos virtuais e das relações entre os indivíduos usuários. Estão inseridas no ciberespaço (LÉVY, 1999), cujo crescimento é agenciado pela conexão entre computadores e celulares. Por assim dizer, "as redes consistem não apenas em pessoas e grupos sociais, mas também em artefatos, dispositivos e entidades" (SANTAELLA; LEMOS, 2010, p. 40), ou seja, consistem na inter-relação entre sistemas de objetos dos quais citamos, e, pessoas, pois "uma rede social é sempre um conjunto de atores e suas relações" (RECUERO, 2009, p. 69), caracterizando-se como "[...] sites na internet que permitem a criação e o compartilhamento de informações e conteúdos pelas pessoas e para as pessoas [...]" (TORRES, 2009, p. 113), onde os consumidores dos conteúdos aí veiculados (criação e compartilhamento coletivo de textos, imagens, sons e vídeos) são, ao mesmo tempo, produtores e consumidores dos mesmos através da informação. Ademais,

\begin{abstract}
uma rede, assim, é uma metáfora para observar os padrões de conexão de um grupo social, a partir das conexões estabelecidas entre os diversos atores. A abordagem de rede tem, assim, seu foco na estrutura social, onde não é possível isolar os atores sociais e nem suas conexões. $O$ estudo das redes sociais na internet, assim, foca o problema de como as estruturas sociais surgem, de que tipo são, como são compostas através da comunicação mediada pelo computador e como essas interações mediadas são capazes de gerar fluxos de informação e trocas sociais que impactam suas estruturas (RECUERO, 2009, p. 24).
\end{abstract}

Passando por processos de evolução, a sociedade esteve sempre a se metamorfosear. Nesse interim, da revolução industrial ocorrida nos séculos XVIII e XIX até o tempo presente, os homens sempre buscaram novos processos, evoluindo-se no seu processo existencial, ao ponto de nos dias atuais termos diferentes formas de trabalhar, produzir, comprar, relacionar, graças a essas (re)evoluções no nosso modo de existir. Para esta finalidade é que também foram criados diversos sites de relacionamentos (redes sociais digitais) que precisam ser tomados como reflexão diante das dinâmicas sociais e educacionais nesse período técnico-científicoinformacional, usadas por grande parte das pessoas que se conectam à internet. Dentre aqueles mais importantes por serem mais conhecidos e acessados, destacamos o Orkut, o Facebook, o Twitter e o Instagram. 


\subsubsection{Orkut}

A rede social Orkut é uma filiada ao Google (site de busca líder mundialmente da internet), criada no ano de 2004. Em tal ferramenta de comunicação e informação, promotora de gostos, difusora de consumos e criadora de hábitos de relacionamentos, notamos que é possível o usuário entrar em uma determinada comunidade, interagir online com amigos e outros usuários que compartilham o mesmo interesse, de acordo com Torres (2009).

Ainda segundo esse autor,

O conceito do Orkut é bastante simples: você cria um perfil, composto por uma série de informações pessoais, fotos e vídeos, e pode convidar membros para serem seus amigos. Esses amigos passam a poder ver as atualizações de seu perfil e a trocar mensagens com você. Além disso, você pode criar uma comunidade, com fórum de discussão, eventos e enquetes, ligada a qualquer tema que imaginar, e convidar pessoas a participarem dela. A entrada na comunidade é feita por meio de um pedido de participação, e o seu perfil mostra as comunidades das quais participa (TORRES, 2009, p. 137).

Como fica claro na afirmação, duas partes estabelecem relações: o usuário através do seu perfil e a comunidade. Tal característica é uma porta aberta para a propaganda de empresas que, buscando aproveitarem-se dos gostos e hábitos desses usuários, lançam seu poder de persuasão na rede. Em outras palavras, "[...] o virtual não é tão virtual quanto parece ser [...]" (SANTOS, SANTOS, 2013, p. 7), já toda uma lógica está por traz dessas ferramentas e que se almejamos uma sociedade e educação crítica e reflexiva, precisamos fazer com que essa questão seja discutida, juntamente com as outras formas de comunicação e informação, presentes na sociedade e nos espaços educacionais.

\subsubsection{Facebook}

O Facebook, outra rede social digital é considerada pelos entrevistados e pelo público usuário dessas ferramentas de comunicação e informação a mais usada nos dias atuais, constituindo-se no maior site de relacionamento do mundo. É uma rede social digital semelhante ao Orkut, no entanto, com alguns aplicativos e ferramentas diferentes. Foi criado por Mark Zuckeberg, um estudante de Harvard e lançado em 4 de fevereiro de 2004 (TORRES, 2009, p. 140).

Ainda conforme esse autor, "no início, o Facebook era restrito aos estudantes de Havard, e aos poucos foi se expandindo para outras universidades. O Facebook se tornou aberto a todos somente dois anos depois, quando passou a aceitar estudantes, pessoas e empresas." (TORRES, 2009, p. 140).

Em termos de privacidade, o Facebook se apresenta mais consistente do que o Orkut, uma vez que tem mais restrições e controles ${ }^{4}$, já que segundo Torres (2009), só se pode ver o perfil completo de alguém se for ou se pertencer ao mesmo grupo dessa pessoa. Percebemos,

\footnotetext{
${ }^{4}$ De uma maneira geral, percebemos que as redes sociais digitais (que se perpetuam no mundo virtual e se tornam parte da cultura dos indivíduos em formação) apresentam fronteiras, difíceis de serem ultrapassadas, apesar de fluidas. Cada usuário possui publicações que demarcam o espaço vivido. É lógico que tais aspectos podem ser transpostos diante das possibilidades que a internet apresenta, mas isso só se solidifica com a sobreposição da subjetividade do indivíduo-usuário e o desejo de conhecer o novo.
} 
nesse sentido, que a rede social digital Facebook "[...] é mais privado que outros sites de redes sociais [digitais], pois apenas usuários que fazem parte da mesma rede podem ver o perfil uns dos outros" (RECUERO, 2009, 172), sendo fundamental ser tomada como elemento de reflexão na sociedade e na Educação.

\subsubsection{Twitter}

O Twitter utilizado por muitos, incluindo celebridades, intelectuais e políticos, é uma ferramenta que impressiona pelos números, desde sua criação no ano de 2006 (SANTAELLA; LEMOS, 2010). Atualmente, por exemplo, conta com mais de 200 milhões de usuários, espalhados ao redor do mundo, conforme sítio eletrônico do Jornal 0 Globo ${ }^{5}$. Sua funcionalidade específica é a de permitir que os usuários divulguem informações pessoais em tempo real, em textos de 140 caracteres (tweets), bastando para isso criar uma conta gratuita, seguir outras pessoas e ser seguido. Para este último aspecto a popularidade do usuário vai estabelecer o número de seguidores; outros, porém adotam a lógica "sigo quem me seguir".

Os tweets variam conforme o usuário e suas especificidades, no entanto, percebemos que em muito dos casos os conteúdos é do tipo contextual, ou seja, os usuários prezam pelos acontecimentos ocorridos no momento do acesso, aqueles que estão em alta na mídia. Em outro momento, os usuários costumam divulgar o seu cotidiano, ações corriqueiras, como é o caso do tweet do usuário abaixo, Figura 1.

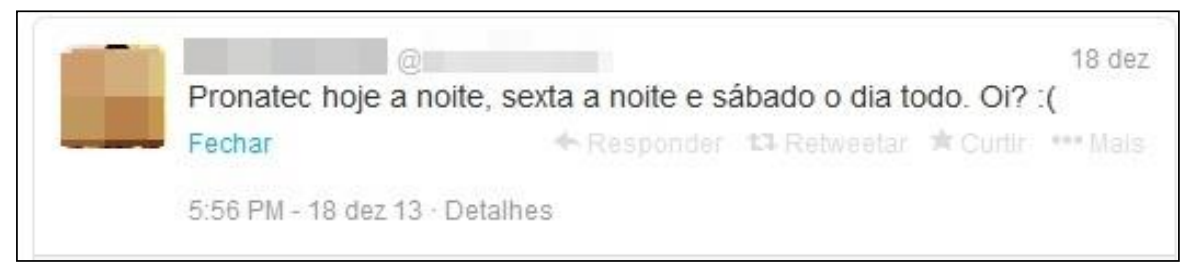

Figura 1: Tweet de Usuário, Relacionado ao seu Cotidiano Fonte: Pesquisa de Campo, 2013.

Como uma arena de conversações e espaço colaborativo (SANTAELLA; LEMOS, 2010), possui na sua plataforma várias ferramentas que possibilitam a interação entre os usuários, é o caso do RT (Retweet), Responder, Curtir, Retweetar e da Hashtag (\#), além do mais, se pode adicionar foto e localização. No caso do Retweet "o uso das letras RT no início de um tweet significa que esse tweet é proveniente de outro usuário e exige a menção do autor logo após essas letras" (p. 107). Já as hashtags "[...] são indexadores de temas, tópicos e/ou palavras-chave que agregam todos os tweets que as contêm em um mesmo fluxo [...]" (p. 108) .

Ademais, na medida em que os usuários se apoderam dos recursos disponíveis (curtir, comentar, retwittar, linkar pelas hashtags, jogar), cria-se uma falsa transferência de poder aos mesmos "cedida" por parte das redes. Com base nisto, e de posse das escolhas dos mesmos, passam, esses sujeitos, a selecionarem aquilo que the é apresentado, seja na forma de aplicativos, jogos, publicações ou seleção de amizades, muito embora cogitem que através de breves cliques tudo podem.

\footnotetext{
5 JORNAL O GLOBO. O Twitter em números. Disponível em: http://oglobo.globo.com/tecnologia/o-twitter-emnumeros-10704107. Acesso em 23 de novembro de 2013.

${ }^{6}$ Para saber mais sobre as outras opções, pesquisar na obra aqui mencionada.
} 


\section{1 .4 Instagram}

O Instagram, por sua vez, é uma rede social criada em 2010 por Kevin Systrom e pelo brasileiro Mike Krieger (PIZA, 2012), para o compartilhamento de fotos e vídeos. No entanto, percebemos durante seu uso que a opção fotos é a mais utilizada pelos usuários como forma de compartilhar os momentos do cotidiano. Seja em casa, no trabalho ou no lazer as pessoas se sentem a vontade para demonstrar a sua vida para os amigos, familiares e até mesmo desconhecidos.

Suas funções são simples e rápidas. Basta um clique e a escolha de um filtro para que as fotos e/ou vídeos se tornem visualizadas pelos usuários do Instagram e de demais redes sociais (Facebook, Twitter, Tumblr, Foursquare e Flickr). Assim como as outras redes sociais digitais mencionadas é "gratuito", porém, para ser utilizado é necessário o uso de um smartphone ou tablet com o aplicativo instalado disponibilizado para sistema Android ou iOS.

Com o Instagram é possível ainda o contato com novas pessoas, através das ferramentas: Explorar e Seguir, Curtir e Comentar posts e da visualização de conteúdos mais populares por meio das hashtags (\#).

Como se pode evidenciar, mediante essa rápida exposição sobre as principais redes sociais digitais em uso na sociedade brasileira, o perfil dos membros usuários dessas ferramentas de comunicação e informação é a grande questão de se colocar em reflexão. Em primeiro lugar, o indivíduo que se propõe fazer parte de uma dessas redes é convidado a preencher um cadastro completo que pode ir de informações básicas da pessoa usuária, até informações profissionais, preferências, gostos esportivos, evidenciando quem é aquele usuário, facilitando ao usuário ser encontrado por outros, bem como facilitando, também, a ação dos grupos econômicos que buscam obter lucro com a difusão de seus produtos nesses ambientes de comunicação e informação. Em segundo lugar, nessas redes é possível as empresas aumentarem o seu potencial de venda.

\section{METODOLOGIA}

Para refletirmos melhor essa realidade, bem como atingirmos o objetivo aqui proposto, realizamos algumas etapas metodológicas que compôs esta pesquisa. A primeira foi uma pesquisa bibliográfica acerca da temática, e análise crítico-reflexiva dos principais debates e conceitos que constituíram nossa forma de ver e apreender o temário em discussão. Para tanto, nos fundamentamos em Recuero (2009); Lévy (1999); Castells (1999); Santos (2008, 2009, 2010), dentre outros, que fornecem elementos críticos e reflexivos da problemática aqui abordada, possibilitando um entendimento maior sobre a realidade empírica estudada.

Uma segunda etapa constituiu-se de levantamento de dados primários, em que através das ferramentas de pesquisa: a) questionário e b) entrevista, obtivemos arcabouço fundamental de comprovação do intento proposto.

\footnotetext{
${ }^{7}$ Resolvemos aspear a palavra gratuito por uma razão simples: para criar uma conta no Instagram ou outra rede social digital, o sujeito precisa de aparatos técnicos comunicacionais, a exemplo do smartphone, tablet e computador, fato que movimenta grandes indústrias desses bens no mercado mundial. Dessa forma, as relações sociais que os usuários estabelecem nessas redes não são tão gratuitas quanto parecem ser.
} 
O questionário, composto com perguntas abertas e fechadas, desenvolvido através da ferramenta Google Drive e divulgado por meio do Facebook, foi aplicado com sujeitos usuários comuns das ferramentas de comunicação e informação (Orkut, Facebook, Twitter e Instagram). Como resultado, obtivemos um universo de 63 usuários partícipes dessa atividade, nos dando, dessa maneira, uma ampliação do leque de informações discutidas mais adiante nesta pesquisa.

Desenvolvemos ainda conversas não formais com usuários destas redes sociais digitais e, realizamos entrevista semiestruturada com docente de uma rede pública de ensino, no sentido de refletirmos as consequências e/ou influências dessas ferramentas no espaço escolareducacional resultante da inserção das novas tecnologias na educação formal. Cumpre lembrar ainda que a escolha desses sujeitos da pesquisa se deve ao fato de representarem a sociedade e a educação, dimensões que buscamos refletir, fazendo parte do próprio universo dos autores deste trabalho.

No que se refere aos métodos aqui utilizados, é importante ressaltarmos que se caracteriza este trabalho como uma investigação exploratória, a qual, segundo Gil (1999) possibilita uma maior familiaridade com os objetos de estudo. Mediante isso, foi preconizado explicitação de abordagens existentes aos temas citados, para assim aprimorar nosso entendimento e oportunizar uma reflexão melhor sobre o mesmo, servindo de base de análise a outros trabalhos. Configura-se, também, este trabalho, como uma abordagem quantitativa no sentido de fazer uso de questionário com perguntas fechadas e abertas, aplicado aos sujeitos mencionados a fim de produzir estatísticas que pudessem auxiliar as análises concomitantes à bibliografia e teoria adotadas.

\section{RESULTADOS E DISCUSSÕES}

\subsection{Redes Sociais Digitais e sua influência na sociedade e educação contemporâneas}

Este subitem tem por objetivo tecer algumas considerações a cerca da influência das redes sociais digitais na sociedade e na educação contemporâneas a partir dos debates já anteriormente tecidos e de uma pesquisa de campo realizada em 2013, com usuários e docente de uma escola da rede pública municipal de ensino, localizada no estado do Rio Grande do Norte, Brasil.

Em nosso levantamento, pudemos constatar que dos usuários pesquisados, $60 \%$, ou seja, 38 deles eram do sexo feminino; e o restante, 40\%, isto é, 25 eram do sexo masculino. Em sua maioria, (51\%), apresentavam uma idade entre 21 e 26 anos; enquanto isto, 30\% disseram ter entre 15 e 20 anos. Ademais, tivemos pessoas entre 27 e 31 anos, (11\%) e outros (8\%) que assinalaram outra idade, não mencionada.

Percebemos com esse diagnóstico que a maioria dos usuários pesquisados é do sexo feminino, fato que atribuímos ao tempo de maior ociosidade da mulher em relação ao homem, perante o mercado de trabalho ${ }^{8}$. Verificamos ainda que a camada populacional que mais faz uso dessas ferramentas de comunicação é considerada jovem, já que a juventude, sendo uma fase da

\footnotetext{
${ }^{8}$ Conforme informações contidas na Pesquisa Nacional por Amostra de Domicílios (Pnad) do Instituto Brasileiro de Geografia e Estatística (IBGE) de 2013, em relação ao gênero, as mulheres ainda são as que mais sofrem com o desemprego no país.
} 
existência humana, é compreendida dos 18 aos 25 anos de idade. As redes sociais digitais que utilizam com mais assiduidade são o Facebook, Twitter, E-mails em geral, Tumblr, Whatsapp, Skype e Instagram, nessa ordem.

Ainda segundo a pesquisa feita, constatamos que o grau de escolaridade dos usuários dessas redes é elevado, pois cerca de $87 \%$ estão ou já estiveram cursando o Ensino Superior ao passo que $13 \%$ cursaram ou estão cursando o Ensino Médio. Sendo assim, a maioria desses sujeitos faz parte de um grupo seleto, que acabam, de certa forma, influenciando os demais usuários, na busca pela popularidade e autoridade (RECUERO, 2009). Nesse sentido, podemos recordar também Sartre (2002, p. 240), quando discute aspectos da existência humana afirmando que, "[...] cada um no interior do campo social definido existe e age em presença de todos e de cada um".

É sabido que as redes sociais digitais possibilitam o encaminhamento a novos espaços de relações, através do acesso a outros "perfis", por meio de links, algo denominado por Recuero (2009, p. 36) como capacidade de migração ${ }^{9}$. Mesmo assim, ressaltamos que muitos usuários com essa garantia, $89 \%$, ainda buscam aqueles(as) que têm vínculo com o seu cotidiano de alguma forma, quer seja pelo mesmo gosto musical, tipo de trabalho, ou outro tipo de afinidade. Isso denota continuidades nas redes sociais digitais, em virtude dos grupos criados e/ou selecionados democraticamente.

Em relação aos conteúdos que os usuários pesquisados costumam publicar e ler constatamos que, em sua maioria, são publicações que possuem ligação com notícias em geral, encontradas em diversos sites, pois $51 \%$ dos entrevistados afirmaram isto. Outros, $31 \%$, publicam conteúdos voltados para o entretenimento; $7 \%$ desses sujeitos preferem a publicação de conteúdos voltados para o meio acadêmico; enquanto isto, 11\% afirmaram divulgar outros conteúdos não informados no questionário aplicado.

Quanto ao quesito leitura, a maioria dos sujeitos pesquisados (69\%) leem mais notícias em geral. Apenas 15\% afirmaram ler conteúdos voltados para o entretenimento; $8 \%$ as publicações vinculadas ao meio acadêmico e $8 \%$ disseram ter outras preferências. Dessa forma, numa relação "todos-todos" (LÉVY, 1999), tal fenômeno pode ocasionar uma espécie de cegueira, no sentido de que os indivíduos podem não vir analisar e refletir aquilo que está disposto/publicado, mas apenas aglutinarem e/ou desperceberem determinadas informações.

Outro aspecto relevante neste trabalho é o fato das publicações serem direcionadas, ou seja, apesar de estarem ao "alcance de todos", são destinadas a atingirem um determinado grupo de pessoas, sejam eles estudantes, religiosos, profissionais, dentre outros exemplos, fato que comprova a hipótese de que existem fronteiras nas redes sociais digitais, ocasionadas pelo uso que se fazem destas. Nesse sentido, tais ferramentas comunicacionais possuem aspectos de um território, já que são configuradas também por um limite ou demarcações que servem para restringir ou possibilitar relações sociais, portanto, são tidas, aqui, como espaços de poder e de controle.

\footnotetext{
${ }^{9}$ Segundo esta autora, "[...] fator característico da interação mediada pelo computador é sua capacidade de migração. As interações entre atores sociais podem, assim, espalhar-se entre as diversas plataformas de comunicação [...]" (RECUERO, 2009, p. 36).
} 
Por assim dizer, é observado que para uma solicitação de amizade ser aceita é preciso um conhecimento sobre a pessoa a ser adicionada. Cerca de $89 \%$ dos entrevistados apontaram isto. Já $5 \%$ responderam que não é preciso conhecer a pessoa; ao passo que $3 \%$ deles afirmaram a necessidade de haver a indicação de terceiros, como anuncia o Gráfico 1.

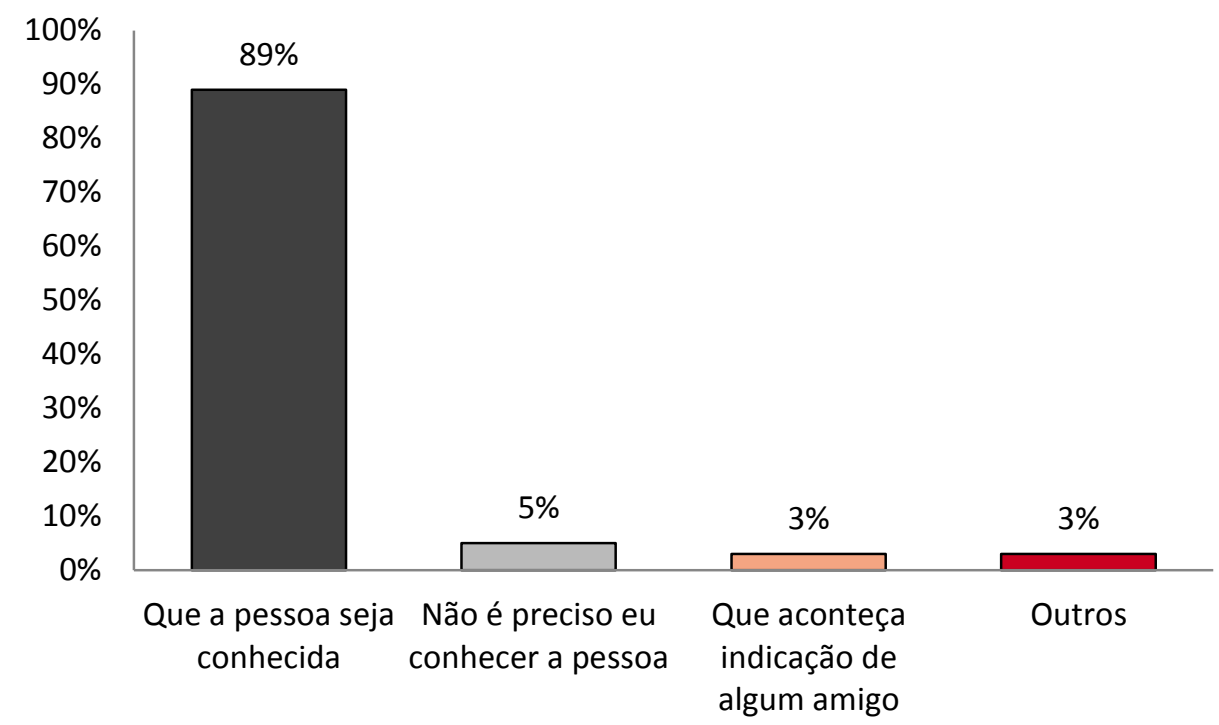

Gráfico 1: Critérios de Aceitação de Solicitação de Amizade pelos Usuários Pesquisados Fonte: Pesquisa de Campo, 2013.

A partir do momento em que o sujeito escolhe e/ou seleciona quem pode ser o seu "amigo" em uma rede social digital, no caso do Facebook, se está demarcando um território, (re)construindo a subjetividade/identidade. Nesse sentido, o usuário cria suas próprias regras e/ou normas, resultando nos critérios de aceitação das relações, estabelecendo, dessa forma, por exemplo, que tipo de conteúdo é importante em sua leitura, o que deve ser publicado para os outros (compartilhamento) e com quem pode promover a comunicação, ou seja, estabelecer interação.

Apesar disso, os vínculos, criados pelas redes sociais digitais são permeados pela fluidez, no sentido de que, como diria Granovetter (1983), os laços serem fraco. Esse autor, ao estudar a nova sociologia econômica busca dar ênfase às relações sociais enfatizando, dentre outros aspectos o impacto dos laços fracos constituídos pelas relações sociais na vida dos indivíduos, o que se aproxima da nossa abordagem, dada a fluidez, liquidez (BAUMAN, 2004), que essas ferramentas constituem no plano social e educacional. Os laços fracos seriam uma oposição aos laços fortes. Os primeiros seriam relações sociais construídas em diferentes contextos sociais marcados pela ausência de relações de parentesco. Os segundos, os laços fortes, seriam as relações sociais caracterizadas por relações de parentesco, ou por um vínculo de amizade mais forte (GRANOVETTER, 1983).

Como espaço de acontecimentos e relações, as redes sociais digitais podem ser consideradas como um dos elementos condicionantes da existência humana moderna, pois a partir do momento em que o homem escolhe utilizar-se de uma dada rede social (projeta-se), ele está assumindo as consequências de sua escolha, (SARTRE, 1984), assim, "o homem nada mais é do que o seu projeto; só existe na medida em que se realiza; não é nada além do conjunto de seus atos, nada mais que sua vida" (p. 13). 
É possível a existência no mundo virtual ${ }^{10}$ ? Nesse trabalho, isto é admissível, pois é evidente a continuidade e a construção de novas histórias de cada membro assíduo ou não. Entendemos aqui a capacidade de o homem se fazer presente no virtual por meio de um sistema de ações e objetos que é a rede, (SANTOS, 2009). Deste modo, podemos manifestar as redes sociais digitais como um lugar situado, fluído e ao mesmo tempo rígido.

De início os usuários são atraídos pelo modismo. Ao se cadastrarem no universo virtual são conduzidos a um novo território e seu desbravamento depende dos interesses e vontades do então membro deste sistema rígido, mas ao mesmo tempo, aberto e flexível. A partir daí, sua maneira de se comunicar e construir amizades muda da mesma forma que a sua rotina, isto porque, há, dentro do mundo virtual, a possibilidade da continuidade e da mudança, ou seja, da totalização em andamento (SARTRE, 2002). Sendo assim, alguns preferem utilizar de sua identidade, em construção, para persistir na sua vivência. Enquanto isto, são movidos a conhecer o diferente, a partir da leitura de publicações dos amigos adicionados, da participação em grupos de discussões, no uso de aplicativos e jogos, o que pode resultar em alterações de pensamento, tidos até então como inquestionáveis, por se fazer presente em suas práticas no mundo real.

A utilidade dessas redes em discussão, que vai além do entretenimento, é formulada em conjunto, tendo em vista o uso do compartilhamento, da opção RT (Retweetar), do ícone Curtir e dos mecanismos para Comentários e Respostas, disponíveis para uso, o que pode ser considerado como um importante fenômeno, por possibilitar aquilo que Lévy (1999) chama de inteligência coletiva.

Nesse sentido, é preciso saber quem são os usuários? O que buscam? Como resposta, por meio do questionário e através de acessos feitos em diversos perfis que foram criados no Orkut, Facebook, Twitter e Instagram, foi possível constatar a presença marcante da diversidade na forma de gênero, idade, cultura e classe social. No tocante ao fato de que estas redes sociais digitais estão sendo usadas em múltiplos espaços e ou regiões com suas especificidades culturais e físicas. De certa maneira, os usuários, buscam por entretenimento, manter novas relações, informações diversas. De outro modo, procuram fazer parte de um grupo preexistente que cresce e chama a atenção por ser inovador e também ideológico.

Destacamos ainda o fato de que persiste o uso impróprio dessas redes digitais. Isto ocorre quando o indivíduo perde a noção de tempo e espaço durante o acesso. Neste caso, o membro priva-se do autocontrole na conexão e torna-se objeto deste meio, no sentido de que, passa a ser mero usuário dessas ferramentas, haja vista o controle técnico e econômico e, sobretudo, intencional não lhes pertencer. Algo que carece ser analisado, pois a história da relação do homem com a técnica demonstrou a necessidade de o primeiro dominar o segundo.

A maioria dos entrevistados pesquisados, (43\%), gastam até 2 horas de seu tempo diário no acesso a uma rede digital. Outros, porém, afirmaram até 1 hora de uso, (33\%). Diferentemente, (15\%), considerado aqui um percentual alto e relevante para a pesquisa, apontaram que chegam a navegar até 4 horas. Ademais, tiveram aqueles que optaram por não

\footnotetext{
10 Para Lévy (1999, p. 49), “é virtual toda entidade 'desterritorializada', capaz de gerar diversas manifestações concretas em diferentes momentos e locais determinados, sem contudo estar ela mesma presa a um lugar ou tempo em particular". Ainda segundo o seu pensamento apesar de não "[...] fixá-lo em nenhuma coordenada espaçotemporal, o virtual é real" (p. 50).
} 
determinar o tempo de acesso, o que representa cerca de (8\%) e que também pode ser um tempo maior ou menor dos descritos.

Nas relações estabelecidas pelas redes sociais digitais existe "o poder simbólico", ou seja, um "[...] poder invisível o qual só pode ser exercido com a cumplicidade daqueles que não querem saber que lhe estão sujeitos ou mesmo que o exercem" (BOURDIEU, 2000, p. 7-8). Neste sentido, em sua forma estruturante (meio comunicacional) é possível encontrar a força das empresas e suas propagandas diante da óptica do mercado, que dominam sobremaneira as funções e ideais, escamoteando a realidade e tornando a opinião homogênea, fato que precisa ser compreendido a partir da visão crítica, de início em sala de aula e/ou em outros espaços de diálogo, em conversações formais ou até mesmo informais.

A atuação das empresas econômicas nas redes sociais digitais é semelhante ao que se praticava no Período Colonial, no Brasil. Neste espaço-tempo a busca pela conquista de novos territórios (exploração) era o principal objetivo daqueles que detinham o poder, como forma de conseguir riquezas. As redes sociais digitais, atualmente, considerada aqui como um território, tornaram-se um meio global ambicionado por diversas empresas, principalmente as internacionais, cujo intuito é o de espalhar o "consumo conspícuo" (VEBLEN, 1965, p. 74) ou consumo desenfreado, desnecessário e formas ideológicas de pensamento, o que carece ser percebido pelos mecanismos de formação crítica, no caso a escola. Nesse sentido, se pode afirmar que rede é poder, por se constituir de uma disputa entre grupos, instituições, empresas e mais do que isto, por está inserida numa lógica mercantil, pois através da união de pontos até então desconexos se pode haver a disseminação de ideologias, pensamentos unívocos, que correspondem à sobreposição do pensamento crítico e a instauração da alienação completa.

De antemão, suas propagandas, quando divulgadas, costumam ser acessadas e consumidas, através de breves cliques, $16 \%$ das pessoas corroboram isto. Notamos ainda outra situação, $23 \%$ afirmaram que as propagandas são acessadas, mas não consumidas. Algo que impressiona ainda é o fato de que $63 \%$ dizem não dar importância para as propagandas. Neste caso, prevalece a opinião de que existem outros mecanismos que chamam mais a atenção dos usuários, dentre eles a informação, comunicação, diversão e lazer; sem falar também no fato de que muitos não clicam nas propagandas por acharem ser vírus.

Todas as redes sociais digitais possuem um determinado termo de uso em que os usuários se comprometem a não infringir nenhuma regra disposta. Inclusive, o usuário poderá ter seu perfil bloqueado, através do cancelamento da conta, permanentemente. Uma das principais razões para isso acontecer, segundo declaração de direitos e responsabilidades do Facebook, acessada em 21 de julho de $2013^{11}$, é o envio de spam por meio da rede, a prática de Bullying ou a presença de publicações pejorativas e pornográficas.

Outra questão pertinente a isso (de que rede é poder) é o fato de alguns usuários terem as suas publicações censuradas, sem qualquer nexo, conforme caso que segue abaixo, Figura 2 .

\footnotetext{
${ }^{11}$ Disponível em: https://www.facebook.com/note.php?note_id=10151420061025301.
} 


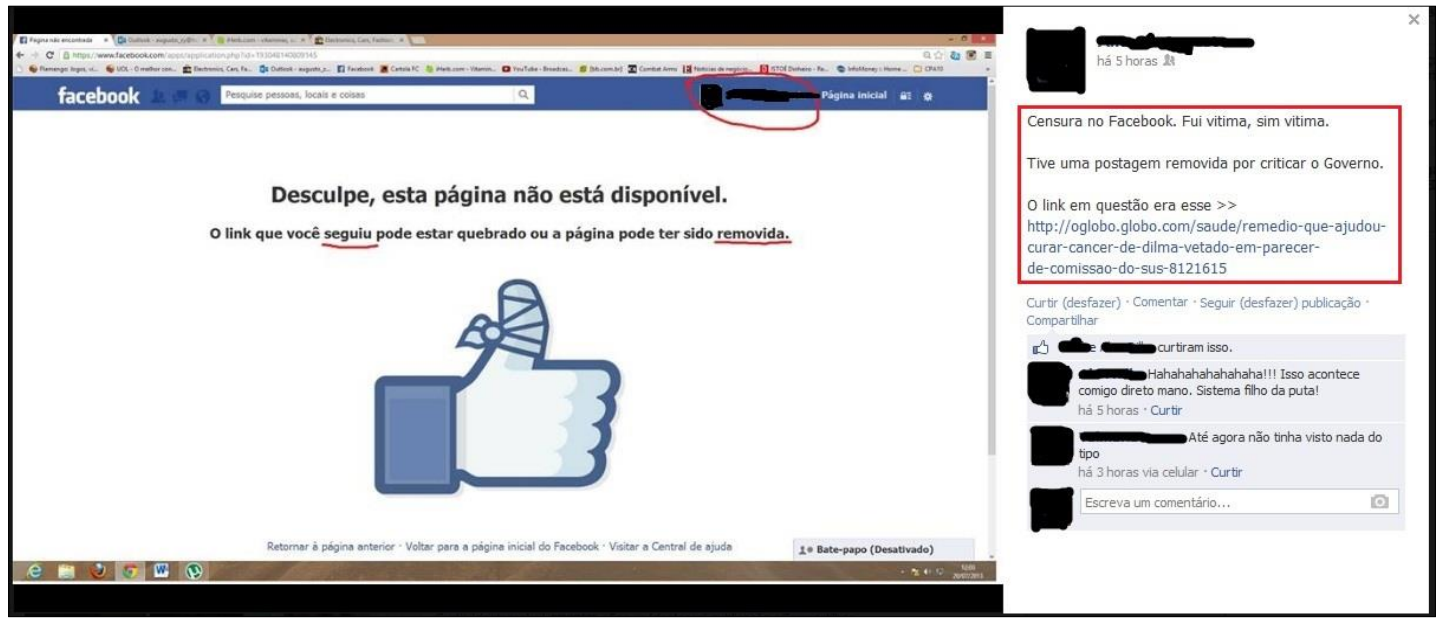

Figura 2: Caso de Usuário da Rede Social Facebook, que Teve sua Publicação Removida Fonte: Pesquisa de Campo, 2013.

Percebemos na Figura 2, que, mais do que uma repressão ao usuário, se estabeleceu um abuso de poder, segundo comentário do mesmo, já que ele não infligiu nenhuma regra estabelecida na declaração de direitos e responsabilidades do Facebook, para que sua publicação viesse a ser removida, conforme se pode constatar no link usado pelo usuário para fazer a crítica ao governo (http://oglobo.globo.com/saude/remedio-que-ajudou-curar-cancer-de-dilma-vetadoem-parecer-de-comissao-do-sus-8121615). Assim, o mesmo publicou em forma de protesto, em 20 de julho de 2013: "Censura no Facebook. Fui vítima, sim vítima" e ainda menciona "tive uma postagem removida por criticar o Governo".

Baseado nisso e em outras afirmações dispostas acima podemos concluir que as redes sociais digitais são formadoras de opinião, o que resulta em pensamentos submissos, alheios a realidade. Os próprios usuários puderam comprovar isto ao afirmarem, cerca de 95\%, que essas ferramentas influenciam as pessoas, enquanto que apenas $5 \%$ disseram o contrário. Esta situação implica que é urgente e necessária a reflexão crítica e reflexiva a cerca do grau de coerção que as redes digitais constroem na sociedade, sobretudo, por parte das instituições formais de ensino.

\section{2 "A Sociedade em Rede": Comunicação e Ação}

Para Santos e Santos (2013, p. 20), as redes sociais digitais alteram as escalas, "desfazem" fronteiras e são extremamente usadas, nesse meio técnico-científico-informacional, como mecanismo de poder e lutas por melhorias. É nesse sentido que talvez Castells (1999), afirme que a revolução da tecnologia da informação, juntamente com a reestruturação do capitalismo tenham introduzido uma nova forma de sociedade, a sociedade em rede.

Essa configuração pode ser melhor exemplificada quando observamos as camadas populacionais e/ou de pessoas da sociedade com a faixa etária mais nova. Tal camada populacional, essa camada mais jovem de pessoas, é protagonista de uma nova geração altamente imbuída em redes sociais digitais, tornando-se informada, "mais escritora" e "mais leitora" de conteúdos veiculados nessas ferramentas comunicacionais do atual período, sendo capaz, portanto de se comunicar de forma impressionante e de maneira que em alguns anos atrás não era possível e/ou sequer imaginada. 
Deve ficar claro para o leitor que a internet é uma das grandes responsáveis por essa mudança evidentemente aliada à capacidade de escolha e suborno das impereis do sistema vigente. Diante disso é possível falarmos em um poder de comunicação instantâneo, que evidencia que o mundo agora se organiza desse ponto de vista, em redes de comunicação e informação antes não possíveis e que essa sociedade virtual parece ter se estabelecido e se tornada para ficar e desenvolver-se junto com a população. Para um melhor aprofundamento dessa realidade consultar Warschauer (2006) e Castells (1999). O primeiro, assim como o segundo entende que estamos organizados em uma sociedade em rede, que tem como elemento fundamental relações sociais permeadas pela instantaneidade da comunicação, possibilitada pela informática e que, a partir do enfoque dado sobre a obra de Warschauer (2006), apesar da exclusão digital que ainda existe, é preciso que se criem mecanismos de inclusão social. Compreendemos, para tanto, que não basta a presença de novas tecnologias de informação e comunicação é preciso que as pessoas saibam utilizá-las em suas relações interpessoais, na produção de informações, na construção de novos conhecimentos e no processo de aprendizagem.

Exemplos de práticas/atos/movimentos sociais ocorridos, mediante a articulação proporcionada por redes sociais digitais podemos destacar, as manifestações ocorridas no Brasil a partir de junho de 2013 e os populares "rolezinhos" (aglomeração de jovens em shoppings resultante de encontros marcados nessas redes). Para Wenger (1998) isto pode ser denominado como comunidades de prática, grupo de pessoas que partilham dos mesmos interesses e criam laços entre si, através da interação, engajamento e aprendizagem coletiva. Tais acontecimentos condizem também com as observações de Pierre Lévy quando este afirma que "[...] a emergência do ciberespaço é fruto de um verdadeiro movimento social, com seu grupo líder (a juventude metropolitana escolarizada), suas palavras de ordem (interconexão, criação de comunidades virtuais, inteligência coletiva) e suas aspirações coerentes" (LÉVY, 1999, p. 125), se fazem concreta nessa sociedade em rede.

Para Castells (1999, p. 497) as redes sociais digitais se configuram como a nova forma de organização social, quando diz que as "redes constituem a nova morfologia social de nossa sociedade, e a difusão da lógica de redes modifica de forma substancial a operação e os resultados dos processos produtivos e de experiência, poder e cultura".

Com esta breve reflexão, percebemos as alterações gradativas pelas quais vive a sociedade em seus paradigmas de interação e relação social, hoje pautados pela popularização da internet, e nas formas de interação, comunicação e informação que a mesma gera a seus usuários. A comunicação mediada por computador, celulares e outros meios já alterou hábitos da cultura de boa parte da população de nossa sociedade, pois a estrutura temporal e espacial que se partilha subjetiva e intersubjetivamente, resultante de um período da história da humanidade marcado pela técnica, ciência e informação (SANTOS, 2009) presente em todos os âmbitos da vida social, impõe "no mundo da vida cotidiana" (BERGER; LUCKMANN, 2012, p. 45) dinâmicas e relações significativas, constituindo-se numa feição que "[...] é parte da realidade global da vida cotidiana, e como tal maciça e irresistível" (Idem, ibidem p. 47). Estas mudanças também estão afetando as organizações e instituições, as quais precisam se adaptar a essas inovações, como é o 
caso das escolas ${ }^{12}$, preocupação já apontada por Santos e Santos (2011) quando discutem a influência desse período no ensino de Geografia. Assim, compreender (ou investigar) as reais influências que as redes sociais digitais, como variáveis desse momento, estão a promover na estrutura escolar é necessidade que se faz.

\subsection{As Redes Sociais Digitais para Além do Espaço Virtual - Sua Influência no Processo de Ensino e Aprendizagem: Breves Considerações}

Conforme já mencionado neste artigo, o período atual denominado técnico-científicoinformacional imprimiu mudanças abruptas e significativas tanto do ponto de vista social, político, econômico e cultural na sociedade contemporânea, quanto da realidade que se configurou e que está se configurando, demandando novas maneiras de ensinar e aprender. Nesse rol está o desafio do lecionar, pois este desafio deverá possibilitar ao educando diferentes maneiras de entendimentos do território que se encontra em constante movimento dados os processos sociais, políticos e econômicos do presente que repercutem diretamente e decisivamente na Educação.

Diante dessa realidade que aí está posta, novas formas de se ensinar e aprender precisam ser valorizadas, em detrimento do conhecimento fragmentado e do saber que se faz presente, desde o século XVIII, com a supremacia do racionalismo.

A valorização de um saber reflexivo como diria Freire (2006) deve ser encarado como uma apropriação necessária competente capaz de dar autonomia ao indivíduo para tornar-se contextualizador e crítico e saber que a competição que se impõe mediante os imperativos do mundo do trabalho precisa ser mais humana e menos agressiva, pois a estruturação de uma sociedade em redes que se configurou nos convida a produzirmos uma educação pautada e instrumentalizada no conhecimento construído coletivamente. Tal realidade demanda comprometimento com uma educação para a vida, para a existência mais humana, sendo uma das competências dos docentes o saber-fazer-uso dos conteúdos técnico-científico, político, pedagógico e sociais aí dispostos, como pode ser representado pelas redes sociais digitais que fazem parte do cotidiano dos alunos que frequentam a educação formal no atual período.

Jamais a necessidade de saber lidar com essas ferramentas de comunicação e informação foi tão urgente quanto esta que aí se apresenta, fazendo com que formação continuada seja uma necessidade (SANTOS, 2012) em todas as áreas profissionais da educação, tanto quanto aquela necessidade de comer e beber. Tal fato se deve à velocidade com que as novas informações, as novas tecnologias, linguagens e comunicações se tomaram, neste período técnico-científicoinformacional, no cotidiano das pessoas. E essa realidade precisa ser incorporada pelos educadores em suas práticas didático e pedagógicas como forma de auxiliar nos processos de ensino e aprendizagem.

Com a reflexão a partir dessas ferramentas em sala de aula, o professor pode demonstrar o quanto é significativo o aumento da participação popular na internet, evidenciando também e, sobretudo a estratégia de empresas dos mais diversos tipos de setores, que a partir de um uso de

\footnotetext{
${ }^{12}$ A cerca da influência dessas ferramentas no ambiente escolar, consultar dentre outras fontes, as edições da Revista Teias, disponíveis em: http://www.periodicos.proped.pro.br/index.php/revistateias/issue/archive; e da Revista de Novas Tecnologias na Educação (RENOTE), disponíveis em: http://seer.ufrgs.br/index.php/renote/ issue/archive.
} 
apelações das mais variadas possíveis buscam se aproximar de seus públicos de interesse (massa de consumidores) ou fabricá-los, estreitando relações, aumentando o lucro com as vendas e desenvolvendo novas estratégias de difusão do consumo que merecem ser pensadas, em todas as disciplinas curriculares, se se quer formar e/ou contribuir com uma formação de sujeitos crítico-reflexivos e autônomos.

Embora percebendo que o poder de comunicação entre as pessoas aumentou nos últimos anos, uma vez que consideramos a comunicação como um poder, sendo que quem a detém passa a ter um diferencial em relação àqueles que não têm, a lógica de estruturação das redes sociais digitais precisa ser discutida e refletida. Nos dias atuais, é notório que as pessoas, por mais simples que sejam e nos lugares mais distantes que habitam, ocupando posições diferentes na sociedade, mediante o aumento significativo de comunicação que têm através das relações sociais e comunicacionais que estabelecem, se posicionam, questionam, se articulam, fazem política. Notamos com essa realidade, portanto, que uma configuração nova implementada e/ou proporcionada pelas redes sociais digitais, é a permissão para qualquer indivíduo transmissor de informação, ser produtor e ser consumidor de informação (MANIERI, 2011), fato de uma realidade socioespacial que precisa ser questionada, refletida e pensada.

Ainda conforme esse autor, "enquanto sujeito de um processo social e de trocas simbólicas, o indivíduo torna-se partícipe do processo de comunicação organizacional num contexto digital" (MANIERI, 2011, p. 6), o que nos leva a reforçar nossas ideias em trabalho anterior (SANTOS, SANTOS, 2013) de que as redes sociais digitais contribuem para a participação social.

No quesito educação, as redes sociais digitais, conforme Chartier (2007) estão a promover maior prática de leitura, bem como ainda a promoção da escrita, apesar de acontecerem numa linguagem informal. Este fato se configura como um deslocamento, pois está a surgir "novos leitores assíduos", não mais aos livros didáticos e ou literários impressos, mas ao mundo virtual com seus materiais digitais, constituído por informação e comunicação síncrona e assíncrona. Conforme Recuero (2009, p. 32) "uma comunicação síncrona é aquela que simula uma interação em tempo real", ao passo que a assíncrona se caracteriza por uma resposta não imediata, segundo essa mesma autora.

Nesse sentido surge, por parte das instituições de ensino, a necessidade de se inserirem nestas redes digitais, como forma de se aproximarem dos alunos-usuários. Para tanto, devem ser criados grupos, páginas, eventos, aplicativos, com o intuito de desmistificar tais ferramentas educativas e também a ideia de educação ultrapassada ou arraigada às tendências, fazendo com isso um aproveitamento das possibilidades educacionais que esses recursos possam oferecer. Em torno disto, os alunos são convidados a refletirem e conhecer melhor os ambientes virtuais em que estão inseridos socialmente, complementando assim, essa forma de aprender com as demais tecnologias educacionais presentes no ambiente escolar, a exemplo do livro didático.

Quanto a isso, é notório que os professores estão tendo problemas no que se refere à introdução das redes sociais digitais no cotidiano dos alunos. A formação inicial do docente não atende a essas necessidades, o que é um desafio, como resultados surgem profissionais despreparados para a prática. Sua relação com a turma deixa de ser contextualizada e passa a ser fragmentada. Não se quer dizer com isto que os profissionais docentes são obrigados a participar de uma rede social digital, contudo, que estejam atentos a este fenômeno; saibam conduzir o 
aluno a crítica, através do diálogo e ou debates em sala de aula. O papel do educador neste caso é o de mediador.

A realidade tem demonstrado o distanciamento entre professores e alunos no que diz respeito às redes sociais digitais, porém isto pode ser superado. Com uma formação inicial insuficiente é preciso a busca por uma formação continuada (reciclagem, atualização) (SANTOS, 2012), que prepare o profissional docente para os desafios do período técnico-científicoinformacional.

No entanto, não é isto que entendem grande parte dos docentes. Encontramos discursos desses profissionais que contribuem para a não disseminação das redes sociais digitais nas escolas, em virtude destas estarem a produzir, nos alunos, desconcentração, erros gramaticais e a falta de tempo para estudos e ou pesquisas. Durante entrevista com uma professora de escola pública, a mesma assegurou que a internet é muito mais atraente e interessante, a leitura de livros é totalmente rechaçada e detestada pela maioria dos adolescentes [...], percebe-se que os jovens se atêm mais ao superficial das redes, ao chamado lixo virtual. Em suma, não percebo avanço qualitativo na leitura e escrita formais em decorrência do uso das mídias (P1). Em contrapartida, compreendemos que é justamente em cima dessas falhas dos alunos que se devem debruçar o trabalho do docente, já que muitos alunos não conseguem se absterem do seu uso no cotidiano.

O uso que estamos instigando quanto a incorporação das redes sociais digitais nos processos didáticos e pedagógicos na educação formal não pode ser entendido única e exclusivamente como referência a ser seguida, sem questionamentos e/ou mudanças. Ademais, não estamos querendo reforçar a antipatia dos alunos pelos livros, mas levarmos os sujeitos educandos e educadores a um pensamento reflexivo que os possibilitem pensar os atores de imposição dessas ferramentas de comunicação, extraindo delas aquilo que é importante para a formação humana e profissional, já que vivemos imbuídos nesses sistemas de objetos, comunicações e informações.

No atual contexto de presença das redes sociais digitais nos espaços escolares, a metodologia de ensino e aprendizagem com ênfase no computador e/ou outras tecnologias não podem ser desprezadas pelos docentes. A esse respeito há vários trabalhos que ajudam nessa empreitada, como é o caso de Kozinets (2010), que em seu capítulo terceiro aponta métodos de pesquisa online que ajudarão o professor nessa atividade com seus alunos; Flick (2004), que discutindo a pesquisa qualitativa, em seu capítulo segundo ao abordar o plano de pesquisa, auxilia o professor nessa tarefa, bem como Lüdcke e Andre (1986); Hine (2005), que na segunda parte dessa obra discute os sites de pesquisa e estratégias de uso dessas ferramentas de ensino e pesquisa; Passerino (2011); Frade (2005), para quem se vive grandes alterações dos conceitos e dos processos que envolvem a leitura e a escrita, devendo o professor atentar-se para essa realidade e, entendemos, buscar nas redes sociais digitais relações com os processos que envolvem a leitura e a escrita, ou seja, aproveitar as múltiplas possibilidades oferecidas pelo momento atual. Todas essas possibilidades se bem aproveitadas pode contribuir para o que Pretto (2013) chama de escola do futuro, ou seja, um ambiente de ensino e aprendizagem que aproveita bem as possibilidades do presente, pois o uso dessas variáveis configura-se como um elemento estruturador carregado de conteúdo, sobretudo porque 
[...] a presença das Tecnologias da Informação e Comunicação (TIC) na educação, hoje com computadores portáteis, smartphone, tablets e uma enorme parafernália tecnológica que, presente na escola, não está conseguindo, em linhas gerais, promover as tão necessárias radicais transformações da educação em nosso país e, sem medo de errar, no mundo (PRETTO, 2013, p. 23).

Tal realidade constitui uma nova forma de ser, de pensar e agir. Nesse sentido, surge, então, um problema por parte daqueles sujeitos que estão mais inter-relacionados a esse ambiente, como é o caso dos docentes, ou seja, como o professor poderá intervir nessa situação, se em sua maioria os acessos são feitos em casa ou pelos aparelhos móveis (Gráfico 2), até mesmo durante o intervalo das aulas? Os pais têm responsabilidade neste caso? Ou é algo que ultrapassa estas instâncias e se torna uma questão global?

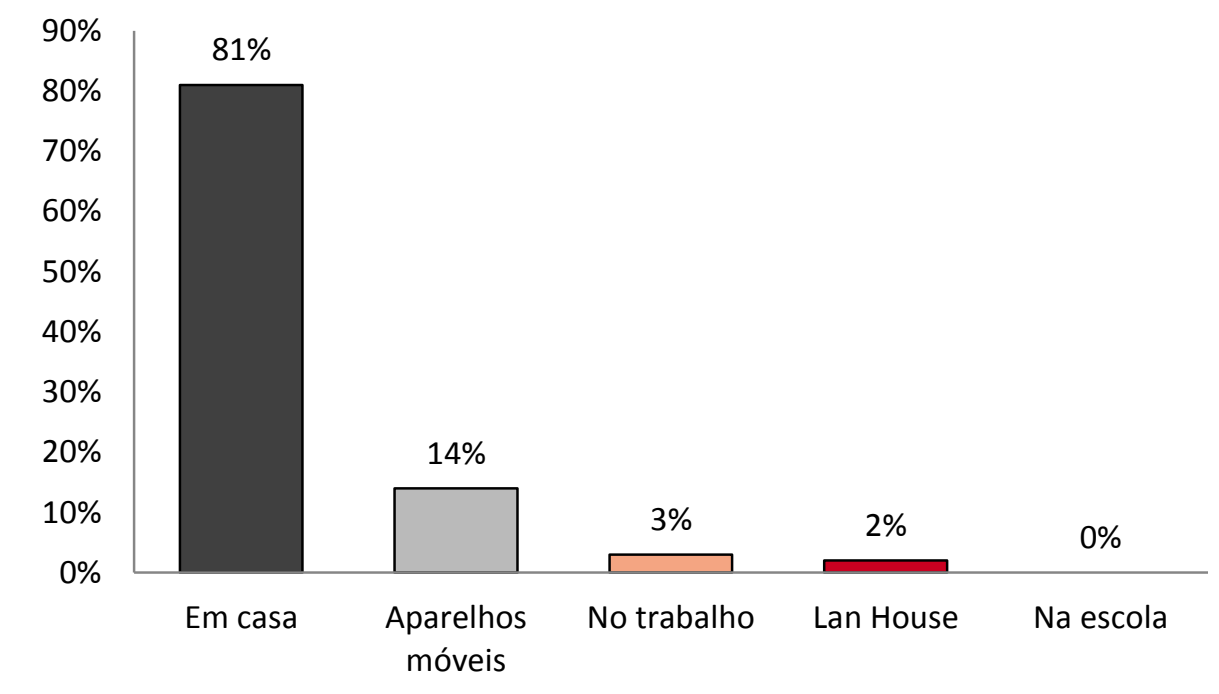

Gráfico 2: Formas e Ambientes de Acesso as Redes Sociais Digitais pelos Entrevistados Fonte: Pesquisa de Campo, 2013.

Como é notório no Gráfico 2, cerca de $81 \%$ dos entrevistados afirmaram utilizar as redes sociais digitais em casa. Um outro dado importante é que $14 \%$ faz uso deste meio através de aparelhos móveis (celular, tablets). No mais, 3\% acessam durante o trabalho; $2 \%$ na Lan House e nenhum dado foi encontrado referente ao uso na escola. Mesmo assim, diante de conversas informais com professores, notamos que os alunos são envolvidos neste universo mesmo em sala de aula por meio das ferramentas supracitadas (os aparelhos móveis). Dessa forma, uma certa porcentagem de uso dessas ferramentas se configuram no ambiente escolar, sendo aí que o professor deve preocupar-se, atentando-se, sobretudo para aqueles alunos que possuem aparelhos móveis.

Encontrar uma resposta para os questionamentos acima é demasiado difícil. Porém, é imprescindível a discussão na sala de aula para que o aluno perceba que diante de um sistema interativo, flexível e aberto, existe também a domestificação do pensamento, parafraseando Morin (2004), diante de um sistema de objetos e ações (SANTOS, 2009) escamoteados no atual meio técnico.

De um modo geral, as redes sociais digitais e a sua presença, mesmo que abstrata, dinamiza o fazer pedagógico, logo, transforma o ensinar em uma arte ainda mais complexa. Curiosamente, mesmo diante deste contexto, o professor, é um dos poucos profissionais que 
conseguiu se sobrepor à cultura do descartável. Muitas profissões não existem mais e outras estão para ser extintas, mediante a influência das máquinas, é o caso do datilógrafo, telegrafista, alfaiate, ferreiro, dentre outras. Porém, isto não significa dizer que o docente é valorizado socialmente, pelo contrário, sua permanência resultou em diversas crises existenciais, portanto, teve que passar por transformações metodológicas, do contrário, seria deixado para trás.

Nesse sentido, compreendemos que estão sendo priorizadas as coisas (objetos) e não os sujeitos em si em solo educativo. Algo que pode ser facilmente notado quando da inserção de computadores nas escolas, decorrente de toda uma política educacional voltada para este fim. Durante sua incorporação, houve profunda estranheza, por parte dos professores. No entanto, isto não foi suficiente para questionamentos ou incertezas, pois "o que nós estamos vivendo hoje é que o homem deixou de ser o centro do mundo" (SANTOS, 1995, n/p, apud TENDLER, 2006) em detrimento de materialidades existentes que constituem a vida cotidiana nesse mundo moderno (LEFEBVRE, 1991).

As redes sociais digitais, como resultado da introdução das telecomunicações nas escolas passam a ser instrumento e conteúdo ao mesmo tempo. De fácil acesso, ocasionam dentre outras coisas a comunicação e a informação imediata, de acordo com as atividades dos usuários. Resta saber se são dinamizadoras de novos conhecimentos e para chegarmos a uma ideia comum é importante investigar a opinião dos usuários.

As redes sociais digitais que engodam por ser instrumento (coisa) que possibilita a informação, comunicação e lazer, segundo resposta dos usuários, correspondem uma nova lógica de relação social, por assim dizer, desafiadora para as práticas de ensino e aprendizagem, no sentido de que há uma disseminação de valores e atitudes homogeneizantes, que implicam em mudanças de pensamento e comportamentos, ou seja, o desenvolvimento de identidade coletiva do tipo negativa, que atinge os ambientes escolares, marcada pela escassez de um pensamento individual e com o domínio de uns sobre os outros, não havendo personalidade, porém cópias, semelhanças, o que merece a atenção dos educadores quanto ao desenvolvimento de uma contra-racionalidade.

Ademais, compreender a importância que a informação e a comunicação têm neste período técnico-científico-informacional é uma realidade que se faz urgente no campo educacional e na vida dos professores que vislumbram novas estratégias de ensino e aprendizagem com seus alunos, em que a comunicação e relacionamento mediadas pelas redes sociais digitais entram como conteúdos significativos desse processo.

\section{CONCLUSÃO}

O objetivo deste trabalho foi contextualizar a influência que as redes sociais digitais exercem sobre os indivíduos, em que foram discutidos possíveis impactos na sociedade e educação decorrentes dessa nova expressão da sociedade contemporânea, a partir de uma pesquisa realizada com usuários e profissionais do ensino.

Tais ferramentas de comunicação e informação representam uma simbiose extremamente significativa entre empresas que desejam colocar no mercado seus produtos e o desejo latente dos indivíduos por se relacionarem através dessas ferramentas comunicacionais, desejo de se interconectarem. Além disso, representam no âmbito educacional a maneira como 
se dão as políticas educacionais em voga, que buscam cada vez mais permear os espaços escolares com as tecnologias de informação e comunicação, que somado à presença dessas materialidades na vida cotidiana da maior parte da população, configura uma nova problemática que os profissionais da educação precisam se debruçar, se dela quiserem extrair bons êxitos.

Nos dias atuais, é notório que as redes digitais, possibilitadas pelos diversos objetos comunicacionais (computadores, celulares com acesso à internet etc.), permite às pessoas criarem novos espaços sociais de relacionamento.

As redes possibilitadas pela internet estão sendo usadas, gerando novas maneiras de participação política, novas formas de entretenimento, novas formas de contato social etc., sendo um fato em que suas estratégias precisam ser discutidas em ambientes formais de ensino, uma vez que diversos aspectos da existência humana, neste período técnico-científicoinformacional, encontram-se sobre influência dessas ferramentas, dentre eles a organização política dos cidadãos quanto à luta por melhorias sociais; o entendimento dos acontecimentos históricos que se passam no mundo; a concepção de autonomia e de vivência no tempo e no espaço; o consumo; a aquisição do conhecimento, bem como o processo de ensino e aprendizagem etc. Nesse sentido, em função da rápida ascensão dessas ferramentas comunicacionais e de inter-relações diversas em evolução contínua, impõem-se a necessidade de instrumentos adequados quanto ao seu desvelamento e entendimento.

\section{REFERÊNCIAS BIBLIOGRÁFICAS}

1. BAUMAN, Z. Amor líquido: sobre a fragilidade das relações humanas. Tradução de Carlos Alberto Medeiros. Rio de Janeiro: Jorge Zahar Editor, 2004.

2. BERGER, P. L.; LUCKMANN, T. A construção social da realidade. Tradução de Floriano de Souza Fernandes. 34. ed. Petropólis: Vozes 2012.

3. BOURDIEU, P. O Poder Simbólico. Tradução de Fernando Tomaz. 2. ed. Rio de Janeiro: Bertrand Brasil, 2000.

4. CASTELLS, M. A sociedade em rede. São Paulo: Paz e Terra, 1999. v. 1.

5. CASTRO, I. E. Seca versus seca: novos interesses, novos territórios, novos discursos no Nordeste. In: CASTRO, I. E.; GOMES, P. C. C.; CORRÊA, R. L. Brasil: questões atuais da reorganização do território. Rio de Janeiro: Bertrand Brasil, 2008.

6. CHARTIER, R. Os livros resistirão às tecnologias digitais. In: Revista Nova Escola, ed. 204, agosto de 2007. Entrevista concedida a Cristina Zahar. Disponível em: http://revistaescola.abril.com.br/lingua-portuguesa/fundamentos/roger-chartier-livrosresistirao-tecnologias-digitais-610077.shtml. Acesso em 22 de fevereiro de 2012.

7. FACEBOOK. Declaração de direitos e responsabilidades. Disponível em: https://www.facebook.com/note.php?note_id=10151420061025301. Acesso em 21 de julho de 2013.

8. FLICK, U. Uma introdução à pesquisa qualitativa. Porto Alegre: Bookman, 2004.

9. FRADE, I. C. A. S. Métodos e didáticas de alfabetização: história, características e modos de fazer de professores. Belo Horizonte: Centro de Alfabetização, Leitura e Escrita. Faculdade de Educação. UFMG, 2005. 
10. FRANCO, A. A revolução do local: globalização, glocalização, localização. São Paulo: Cultura/AED, 2003. Disponível em: https://docs.google.com/folderview?docld=0B-YLV8egG wSUOERWY1dwdWg2NEE\&id=0B-YLV8egGwSuelBsRk5pODRyQkU. Acesso em 18 de janeiro de 2011.

11. _ _ O poder nas Redes Sociais: versão preliminar resumida. 2009. In: Escola de Redes. Disponível em: http://escoladeredes.net/profiles/blogs/o-poder-nas-redes-sociais?xg_source =activity. Acesso em 18 de janeiro de 2011.

12. FREIRE, P. Pedagogia da Autonomia. 34. ed. São Paulo: Paz e Terra, 2006.

13. GIL, A. C. Métodos e técnicas de pesquisa social. São Paulo: Atlas, 1999.

14. GRANOVETTER, M. The Strength of Weak Ties: anetwork theory revisited.In: Sociological Theory (Blackwell), v. 1, 1983. p. 201-233. Disponível em: http://www.soc.ucsb.edu/ faculty/friedkin/Syllabi/Soc148/Granovetter\%201983.pdf. Acesso em 3 de outubro 2014.

15. HINE, C. Virtual Methods: issues in social research on the internet. Oxford: Berg, 2005. Disponível em: http://www.questia.com/read/120652276/virtual-methods-issues-in-socialresearch-on-the. Acesso em 3 de outubro 2014.

16. IBGE - Instituto Brasileiro de Geografia e Estatística. Pesquisa Nacional por Amostra de Domicílios. Rio de Janeiro, 2013.

17. JORNAL O GLOBO. O Twitter em números. Disponível em: http://oglobo.globo.com/ tecnologia/o-twitter-em-numeros-10704107. Acesso em 23 de novembro de 2013.

18. _. Remédio que ajudou a curar câncer de Dilma é vetado em parecer de comissão do SUS. Disponível em: http://oglobo.globo.com/saude/remedio-que-ajudou-curar-cancer-dedilma-vetado-em-parecer-de-comissao-do-sus-8121615. Acesso em 20 de julho de 2013.

19. KOZINETS, R. V. Nethnography: doing ethnographic research online. London: Sage, 2010. Disponível em: http://books.google.com.br/books?id=QNDaeutR9v4C\&printsec= frontcover $\& \mathrm{hl}=\mathrm{pt}-\mathrm{BR} \&$ source=gbs_ge_summary_r $\&$ cad $=0 \# \mathrm{v}=$ onepage $\& \mathrm{q} \& \mathrm{f}=\mathrm{false}$. Acesso em 3 de outubro 2014.

20. LeFEBVRE, H. A vida cotidiana no mundo moderno. São Paulo: Ática, 1991.

21. LÉVY, P. Cibercultura. Tradução de Carlos Irineu da Costa. São Paulo: Editora 34, 1999.

22. LÜDKE, M.; ANDRÉ, M. E. D. A. Pesquisa em educação: abordagens qualitativas. São Paulo: Pedagógica e Universitária, 1986.

23. MANIERI, T. Os Desafios da Comunicação Organizacional na era das Mídias Digitais. In: Anais do XXXIV Congresso Brasileiro de Comunicação de Ciências da Comunicação - Recife, PE - 2 a 6 de setembro de 2011.

24. MORIN, E. A cabeça bem-feita: repensar a reforma, reformar o pensamento. 10. ed. Rio de Janeiro: Bertrand Brasil, 2004.

25. PASSERINO, L. M. Salas de Recursos, Tecnologia Assistiva e Processos de Inclusão a Partir da Perspectiva Sócio-histórica. In: MORAIS, S. C. (Org.). Educação Inclusiva: diferentes significados. Porto Alegre: Avangraf, 2011. p. 67-77.

26. PIZA, M. V. O fenômeno Instagram: considerações sob a perspectiva tecnológica. 2012. 48 f. Monografia (Graduação em Sociologia). Universidade de Brasília, Brasília. 
27. PRETTO, N. L. Uma escola sem/com futuro: educação e multimídia. Apresentação, Ismar de Oliveira Soares. 8. ed. rev. e atual. Salvador/BA: EDUFBA, 2013.

28. RECUERO, R. Redes Sociais na Internet. Porto Alegre: Sulina, 2009. (Coleção Cibercultura).

29. RENOTE, Revista de Novas Tecnologias na Educação. Por Edição. Disponível em: http://seer.ufrgs.br/index.php/renote/issue/archive. Acesso em 8 de janeiro de 2013.

30. REVISTA TEIAS. Por Edição. Disponível em: http://www.periodicos.proped.pro.br/index.php/ revistateias/issue/archive. Acesso em 8 de janeiro de 2014.

31. SANTAELLA, L.; LEMOS, R. Redes sociais digitais: a cognição conectiva do Twitter. São Paulo: Paulus, 2010. (Coleção Comunicação).

32. SANTOS, M.; SILVEIRA, M. L. O Brasil: território e sociedade no início do século XXI. 4. ed. Rio de Janeiro: Record, 2002.

33. SANTOS, M. In: TENDLER, S. Encontro com Milton Santos - ou o mundo global visto do lado de cá. Ano: 2006 Cor, Dvd. Direção: Silvio Tendler.

34. __ Técnica, Espaço, Tempo. 5. ed. São Paulo: Edusp, 2008. (Coleção Milton Santos; 11).

35. _. A natureza do espaço: técnica e tempo, razão e emoção. 4. ed. 5a . reimpr. São Paulo: Edusp, 2009. (Coleção Milton Santos; 1).

36. __ Por uma outra globalização: do pensamento único à consciência universal. 19. ed. Rio de Janeiro: Record, 2010.

37. SANTOS, V. L. C. Formação Continuada e Ensino À Distância: um estudo de caso sobre o Proinfo Integrado em Serrinha dos Pintos (RN). 2012. 88 f. Monografia (Licenciatura). Departamento de Educação, Universidade do Estado do Rio Grande do Norte (UERN).

38. SANTOS, J. E.; SANTOS, V. L. C. O período técnico-científico-informacional e o ensino de Geografia: algumas notas. In: Revista Caminhos de Geografia. Uberlândia, v. 12, n. 39, set/2011. p. 168-180.

39. _. Geografia dos protestos e meio comunicacional: redes sociais digitais e manifestações populares. In: Revista Movimentos Sociais e Dinâmicas Espaciais, Recife, v. 02, n. 02, 2013. p. 7-22.

40. SARTRE, J-P. O existencialismo é um humanismo. São Paulo: Abril Cultural, 1984.

41. C Crítica da razão dialética: precedido por questões de método. Rio de Janeiro: DP\&A, 2002.

42. TORRES, C. A bíblia do marketing digital. São Paulo: Editora Novatec, 2009.

43. VEBLEN, T. Consumo Conspícuo. In: . A teoria da classe ociosa. Tradução de Olivia Krãhaenbühl. São Paulo: Livraria Pioneira Editora, 1965.

44. WENGER, E. Communities of practice: learning, meaning, and identity. New Work: Cambridge University Press, 1998. 